\title{
Optimal viewing angles of intraoperative fluoroscopy for detecting screw penetration in proximal humeral fractures: a cadaveric study
}

\author{
Qiuke Wang ${ }^{\dagger}$, Yifei Liư ${ }^{\dagger}$ Ming Zhang, Yu Zhu, Lei Wang ${ }^{*}$ and Yunfeng Chen ${ }^{*}$
}

\begin{abstract}
Background: To identify the optimal viewing angles for every proximal screw in PHILOS plate-fixed proximal humeral fractures.

Methods: Three fresh-frozen human cadaveric bodies with six intact shoulders were studied. All three bodies were put in the beach chair position and PHILOS plates were placed on the proximal humerus. Head screws penetrating $1 \mathrm{~mm}$ into the joint were fitted one by one. Fluoroscopy was conducted in the $180^{\circ}$ horizontal plane and the $120^{\circ}$ coronal plane to analyze each screw's penetration in every shoulder. Images were taken every $5^{\circ}$, then all images were analyzed to identify the sensitive angles.

Results: The range of optimal viewing angles to visualize penetration of every head screw was identified. In the coronal plane, the angles in the range between $0^{\circ}$ and $10^{\circ}$ were sensitive to all screws except No. 8 and No. 9 . Furthermore, penetration of screws No. 8 and 9 could not be identified on any axillary view, but could be identified in the horizontal plane from $-30^{\circ}$ to $-10^{\circ}$ and from $10^{\circ}$ to $35^{\circ}$ respectively.

Conclusions: We recommend a $0^{\circ}-10^{\circ}$ axillary view with $30^{\circ}$ arm abduction combined with two horizontal angles in the range of $-30^{\circ}$ to $-10^{\circ}$ and $10^{\circ}$ to $35^{\circ}$ for routine fluoroscopy during surgery. Our results will be helpful in avoiding primary screw penetration.
\end{abstract}

Keywords: Proximal humeral fracture, Screw penetration, Complication, Fluoroscopy, Surgery, Trauma

\section{Background}

Proximal humeral fracture accounts for approximately $5 \%$ of all bone fractures, and the rate is rising with the increasing age of the population [1-3]. Although roughly $80 \%$ of these fractures can be treated conservatively, the rest, which are considered as displaced fractures, are recommended to be fixed by surgery [4]. Since locking plates, especially the PHILOS plate (Proximal Humerus Internal Locking System, Depuy Synthes, Warsaw, IN, USA), are becoming more and more popular to achieve satisfactory outcomes in fixing proximal humeral

\footnotetext{
* Correspondence: wanglei2264@126.com; drchenyunfeng@sina.com ${ }^{\dagger}$ Qiuke Wang and Yifei Liu contributed equally to this work.

Department of Orthopedic Surgery, Shanghai Jiao Tong University Affiliated Sixth People's Hospital, 600 Yishan Road, Shanghai 200233, People's Republic of China
}

(c) The Author(s). 2018 Open Access This article is distributed under the terms of the Creative Commons Attribution 4.0 International License (http://creativecommons.org/licenses/by/4.0/), which permits unrestricted use, distribution, and reproduction in any medium, provided you give appropriate credit to the original author(s) and the source, provide a link to the Creative Commons license, and indicate if changes were made. The Creative Commons Public Domain Dedication waiver (http://creativecommons.org/publicdomain/zero/1.0/) applies to the data made available in this article, unless otherwise stated.

fractures [5-8], a high rate of complications has been reported related to the use of plates, of which screw penetration is the most frequent $[4,6,9-11]$. Patients with screw penetration may experience severe pain and require subsequent revision surgery to remove the internal plate, which has a significant effect on rehabilitation. Screw penetration includes both primary and secondary screw penetration. The incidence of primary screw penetration is proximately $14 \%$ [5] it occurs during surgery and is considered to be an avoidable complication, preventable by careful operation and appropriate fluoroscopic detection during surgery. However, knowledge of the appropriate fluoroscopic detection is inadequate. Spross et al. [12] found that only the combination of four projections of fluoroscopic detection (neutral, $30^{\circ}$ external rotation, $30^{\circ}$ internal rotation and axial in $30^{\circ}$ ) 
could achieve $100 \%$ sensitivity and that standard radiographs (anteroposterior and outlet) missed almost half the instances of primary screw penetration in fractures fixed with the PHILOS plate. The process required to complete four angles of fluoroscopic detection during surgery is tedious and time-consuming, which means that primary screw penetration can easily be missed during routine surgeries. Two studies of Theopold et al. reported that intraoperative 3D fluoroscopy enabled 100\% detection of the screw perforations [13, 14]. However, 3D fluoroscopy equipment was not available in most operating rooms while regular X-ray projector (c-arm) was always equipped.

The aim of our study therefore was to explore the optimal viewing angles of intraoperative fluoroscopy for every proximal screw in PHILOS plate-fixed proximal humeral fractures, and then suggesting some intra-operative fluoroscopy angles for avoiding screw penetration.

\section{Methods}

This study was approved by ethics of committee of Shanghai sixth people's hospital, the approval number is 2016-ky-005, and all donors had signed agreement about further cadaveric research and education before body donation. Three fresh-frozen human cadaveric bodies with six intact shoulders were obtained, which comprised 2 females and 1 male, with a mean age of 72.2 years (range 64-82). All the specimens included the entire scapula, clavicle, humerus and intact associated soft tissues. Gross examination was performed and clinical histories were reviewed to exclude any history of bone diseases.

\section{Preparation of specimens}

All three bodies were put in a beach chair position to simulate the intraoperative situation. The PHILOS plates were placed on the proximal humerus, $5 \mathrm{~mm}$ lateral to the bicipital groove and $8 \mathrm{~mm}$ distal to the tip of the greater tuberosity, in all shoulders through the standard deltopectoral approach. Two non-locking screws were initially placed in the shaft holes to fix the plates in position. Second, we simulated the methods used in the study by Spross et al. [12]; the subscapularis muscle was tenotomized close to the lesser tuberosity and the anterior capsule was vertically incised to gain full sight into the joint and of the humeral head, so that drilling of head screws could be visually controlled to avoid perforating the head. Lastly, the lengths of the head screws were chosen according to the measurement of the lengths of the drill holes, and nine head screws were placed in the humeral head in each shoulder.

\section{Imaging investigation}

Head screws were numbered to facilitate identification and recording (Fig. 1). The No. 1 screw was removed (prepared above) and a longer screw was inserted to penetrate the head, the length was controlled to penetrate $1 \mathrm{~mm}$ beyond the surface of the head under direct vision (Fig. 2). After exchanging the screws, the joint was sutured and the arm was placed in a neutral position. To simulate the anteroposterior projections, the $\mathrm{c}$-arm was positioned in the anteroposterior direction (perpendicular to coronal plane of the body and c-arm on the horizontal plane) and it was set as $0^{\circ}$. Then the c-arm was rotated clockwise (overlooked), and an image was obtained every $5^{\circ}$ up to $90^{\circ}$, resulting in 18 images being obtained. After that, the c-arm was reset at $0^{\circ}$ and rotated anti-clockwise up to $90^{\circ}$, and again an image was obtained every $5^{\circ}$. In total, 37 images were obtained in the $180^{\circ}$ horizontal plane. In order to facilitate data recording, for the left shoulder we set the angle on the right as "+" and on the left as "-"; we then used the opposite convention for the right shoulder (Fig. 3). During this process, the body and the arm were kept still.

In order to simulate the axillary view, the c-arm was placed on the coronal plane of the body and the arm

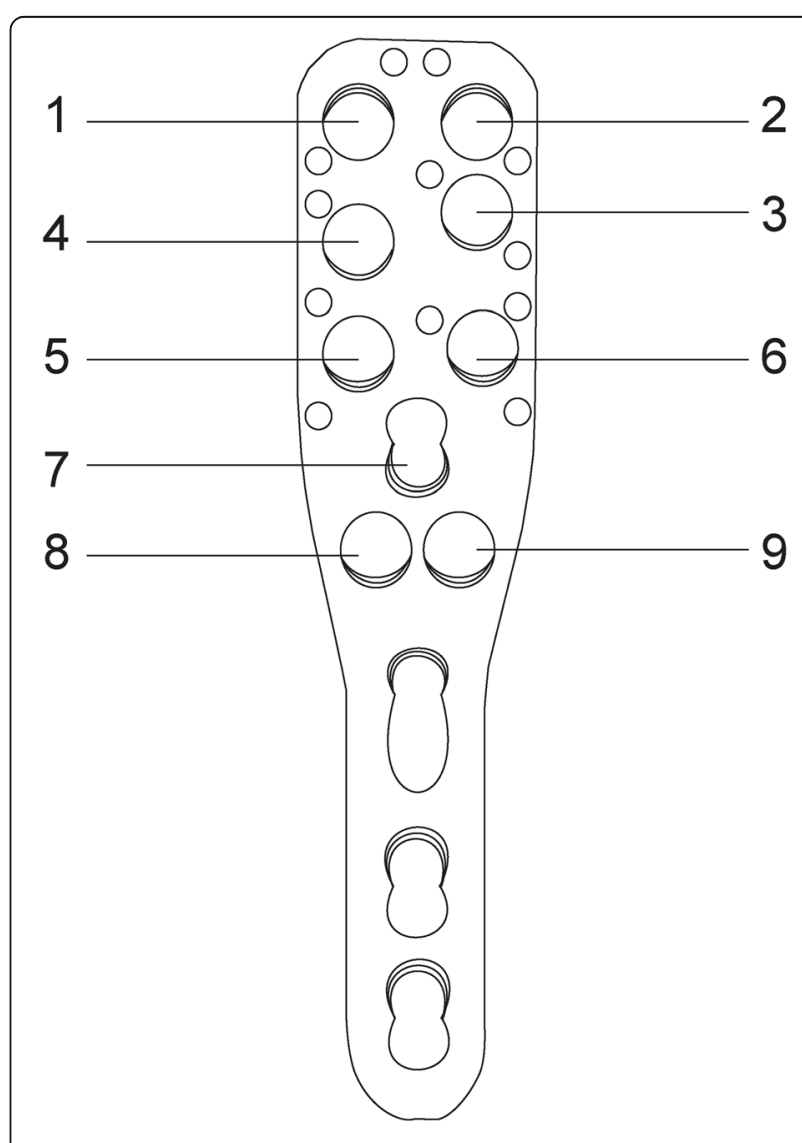

Fig. 1 The numbering of the head screws (holes) on the PHILOS plate 


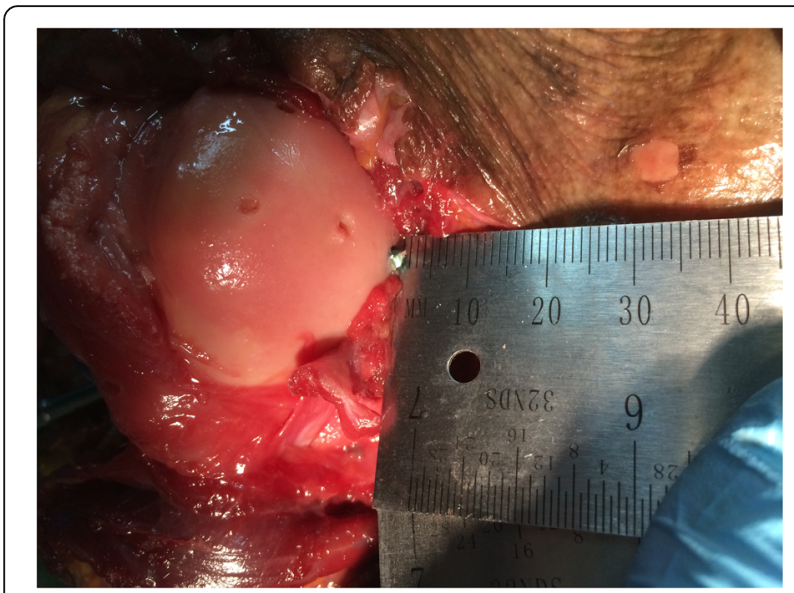

Fig. 2 Each head screw penetrates the humeral head to $1 \mathrm{~mm}$ under visual control

was placed at $30^{\circ}$ of abduction (Fig. 4). Taking the left shoulder as an example, the standard axillary view was set as $0^{\circ}$, then the c-arm was rotated clockwise (sighted from the anterior to the posterior of the body), and an image was obtained every $5^{\circ}$ up to $90^{\circ}$ (equivalent to the axillary view with the arm at $120^{\circ}$ of abduction). After that, the c-arm was reset at $0^{\circ}$ and rotated anti-clockwise up to $30^{\circ}$ (equivalent to the axillary view with the arm at $0^{\circ}$ abduction) and an image was obtained every $5^{\circ}$. A total of 25 images were obtained on the $120^{\circ}$ coronal plane, and as above, in the left shoulder we set the angle on the right as "+" and on the left as "-", while for the right shoulder, the opposite convention was used. During this process, the body was kept still with the arm in $30^{\circ}$ of abduction.

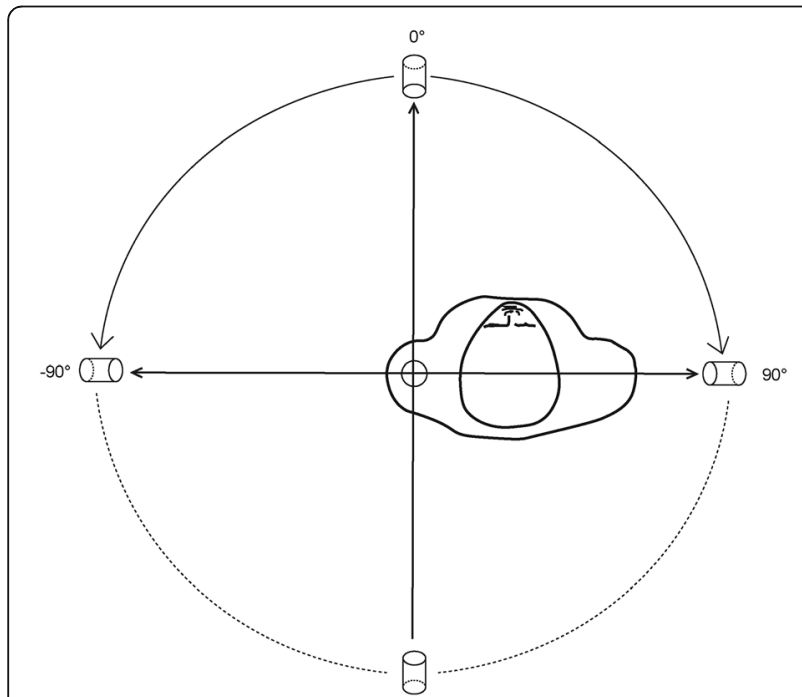

Fig. 3 Taking the left shoulder as an example, radiographic projection was conducted in a $180^{\circ}$ horizontal plane. Radiographic images were taken every $5^{\circ}$

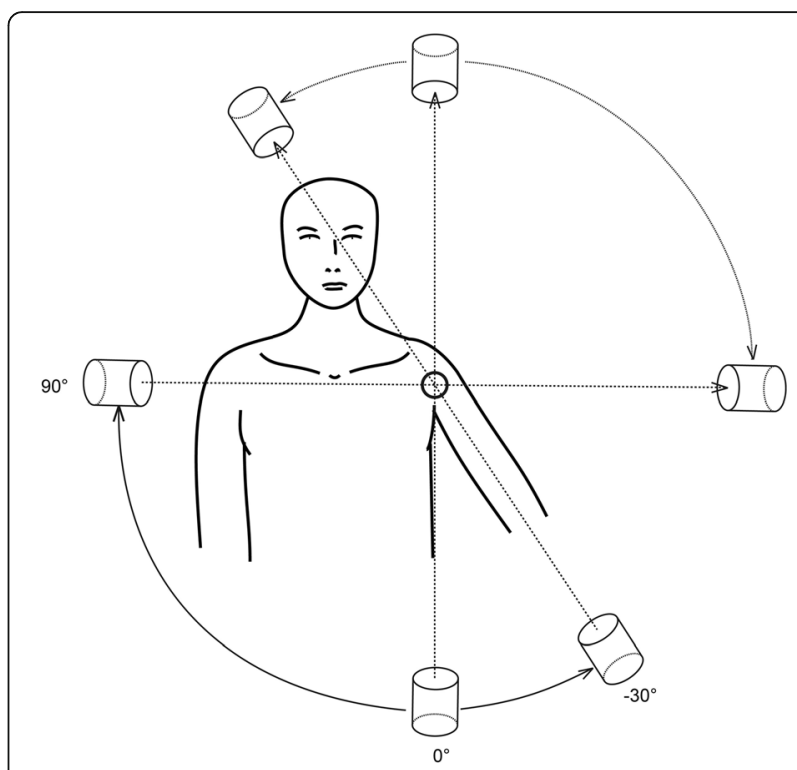

Fig. 4 Taking the left shoulder as an example, the arm was positioned at $30^{\circ}$ of abduction, and radiographic projection was conducted in a $120^{\circ}$ coronal plane. Radiographic images were taken every $5^{\circ}$

Overall, a total of 62 images were obtained for the penetration of No. 1 screw. The same method was then applied for the imaging investigation of penetration of the next 8 screws, to give a total of 558 images from one shoulder. All 6 shoulders underwent the same process and $558 \times 6$ images were collected.

\section{Imaging analysis}

All images were numbered and were independently and randomly reviewed for screw penetration (yes/no) by two experienced attending doctors. The two doctors were blinded to the experimental design and process. All discordant cases were reevaluated by a third examiner, and the results were assigned by consensus of the three examiners. Based on these results, for each shoulder, we were able to draw a viewing angle range to detect penetration of every head screw.

\section{Statistical analysis}

Statistical analysis was performed using the statistical program SPSS version 20.0 (IBM Corp., Armonk, NY, USA). The optimal viewing angle range of every screw was set between the average minimum and maximum of the six shoulders. In this study each screw has an angle range in each shoulder, so the average of the six angle ranges was calculated for each screw, with the lower boundary set as the average of the lower boundary of the six angle ranges and the higher boundary as the average of the higher boundary of the six angle ranges. In order to simplify clinical application, all the angles were measured to the nearest multiple of five greater 
than the average lower value for the lower boundary, for example if the average value was 8 we chose 10; and we chose the first multiple of five less than the average higher value for the higher boundary, for example if the average value was 8 we chose 5 (Fig. 5).

\section{Results}

As each screw was positioned one by one to penetrate the humeral head in each shoulder, the same radiographic process was performed as described above, and screw penetrations could be identified on the images (Fig. 6).

After calculating the average minimum and maximum sensitive angles of all six shoulders, the optimal range of viewing angles to visualize penetration of every head screw was identified. Taking No. 1 screw as an example, the viewing angles ranged from $-35^{\circ}$ to $20^{\circ}$ in the horizontal plane (Fig. 5a) and $-5^{\circ}$ to $45^{\circ}$ in the coronal plane (Fig. $5 b)$. All viewing angle ranges are collated in Fig. 7. In the coronal plane, the angles in the range between $0^{\circ}$ and $10^{\circ}$ were able to visualize all screws except No. 8 and 9. Furthermore, penetration of screws No. 8 and 9 could not be identified on any axillary view, but could be identified in the horizontal plane only. In this study, we maintained the body and arm in a fixed position, therefore theoretically, our angle data could be transferred to another type of fluoroscope in which we could rotate the arm or move it without moving the c-arm. The internal and external rotation of the arm in anteroposterior projections is equal to the rotation of the c-arm in the horizontal plane, and the transferred data are presented in Fig. 8.

\section{Discussion}

The PHILOS plate is a widely-used implant for fixing proximal humeral fractures; it is designed to position divergent screws in the humeral head in order to increase screw purchase; however, its unique design makes it difficult to identify the screws' position during surgery. Screw penetration is found to occur frequently during surgery as well as at follow-up, resulting in damage to the glenoid fossa caused by the screw tip and causing the patient to suffer severe pain [14-18]. Screw penetration of PHILOS plate is the primary object of our study, and our results concerning the optimal viewing angle ranges for intraoperative fluoroscopy to detect screw penetration lead the way for surgeons. Traditional standard anteroposterior and lateral fluoroscopy may miss penetration of at least 3 screws (No. 5, 8 and 9), while for three orthogonal views, in the trauma-series of $\mathrm{x}$-rays (true glenoid anteroposterior, trans-scapular lateral and axillary views), penetration of screw No. 8 can still be missed. This may be the reason why screw penetration remains the most frequent complication. Penetration of screws No. 8 and 9 could not be identified on our axillary

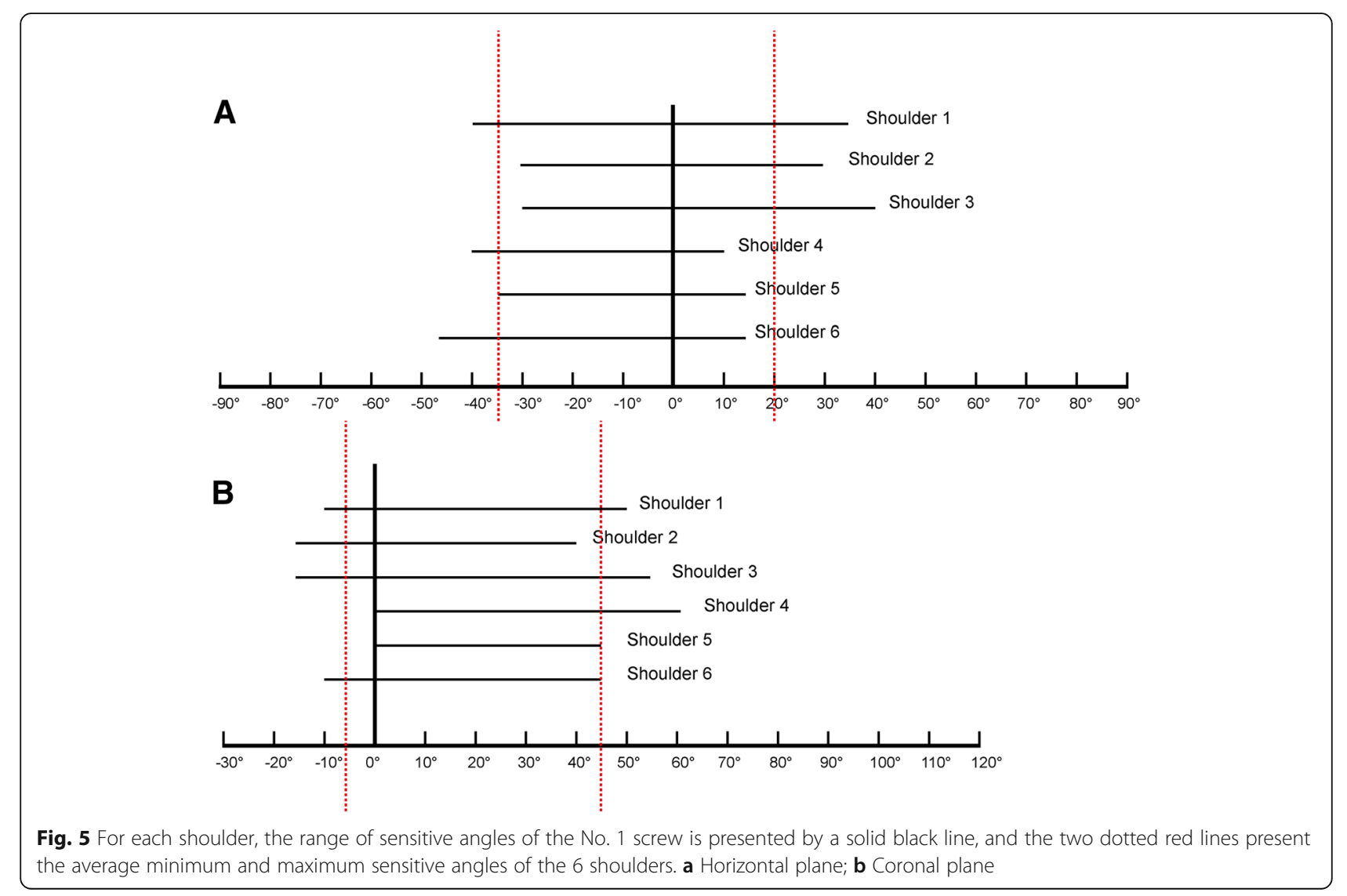




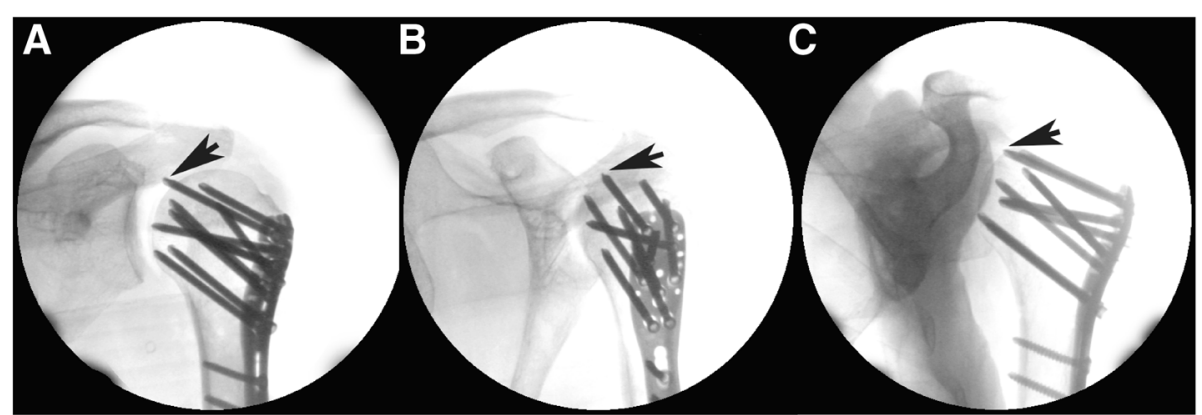

Fig. 6 Three images present three different viewing angles in the horizontal plane for the No. 1 screw in shoulder 1. Screw penetrations can be identified in three viewing angles, a $0^{\circ} ; \mathbf{b} 40^{\circ} ; \mathbf{c}:-35^{\circ}$

views; this may be because these two screws are positioned on the lower part of the spherical head, so that the superior part may easily hide the $1 \mathrm{~mm}$ cut out and our view angles are limited between $-30^{\circ}$ and $90^{\circ}$.

Some instances of penetration found at follow-up may have happened during surgery and have been missed because of inadequate fluoroscopy. In a study by Charalambous et al. [5], 4 of 25 patients were found to have screw penetration at follow-up, and subsequent review of the intra-operative radiographs showed that the penetration was missed intra-operatively in one case.
Thanasas et al. [19] highlighted the use of intraoperative fluoroscopy and recommended fluoroscopy in at least two different planes to avoid screw penetration. However, in their study, little information is available about which angles or planes have a high sensitivity for detecting screw penetration during surgery. Spross et al. [12] conducted a study to test some widely-used radiographic projections for detecting screw penetration, and found that anteroposterior and outlet radiographs, especially in internal rotation, may miss almost half the instances of screw penetration, while the standard axillary view $\left(30^{\circ}\right.$

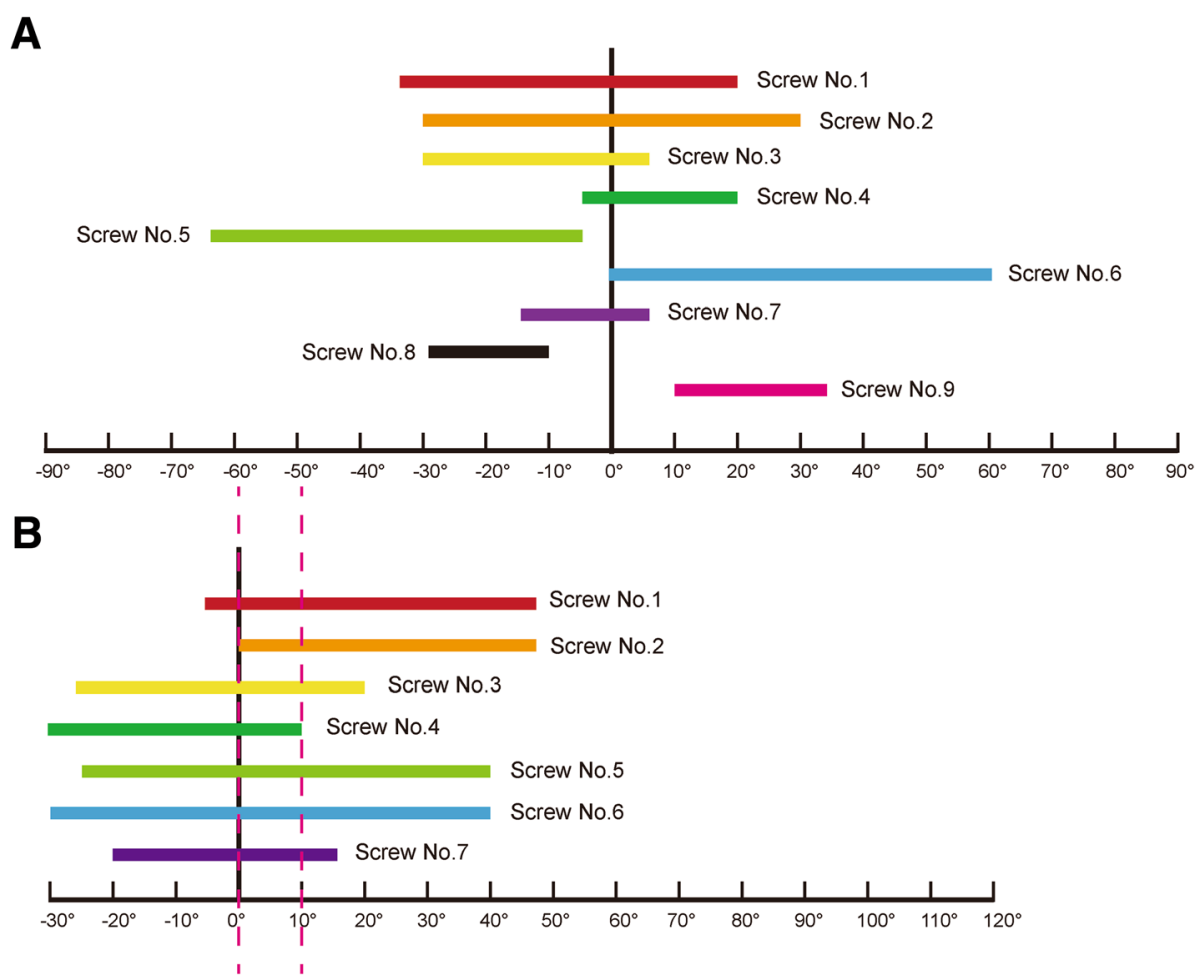

Fig. 7 The optimal viewing angles for each screw are indicated in the diagram by colored bands. a Horizontal plane; b Coronal plane. The angles between the two dotted red lines provide sensitive visualization of all seven screws 


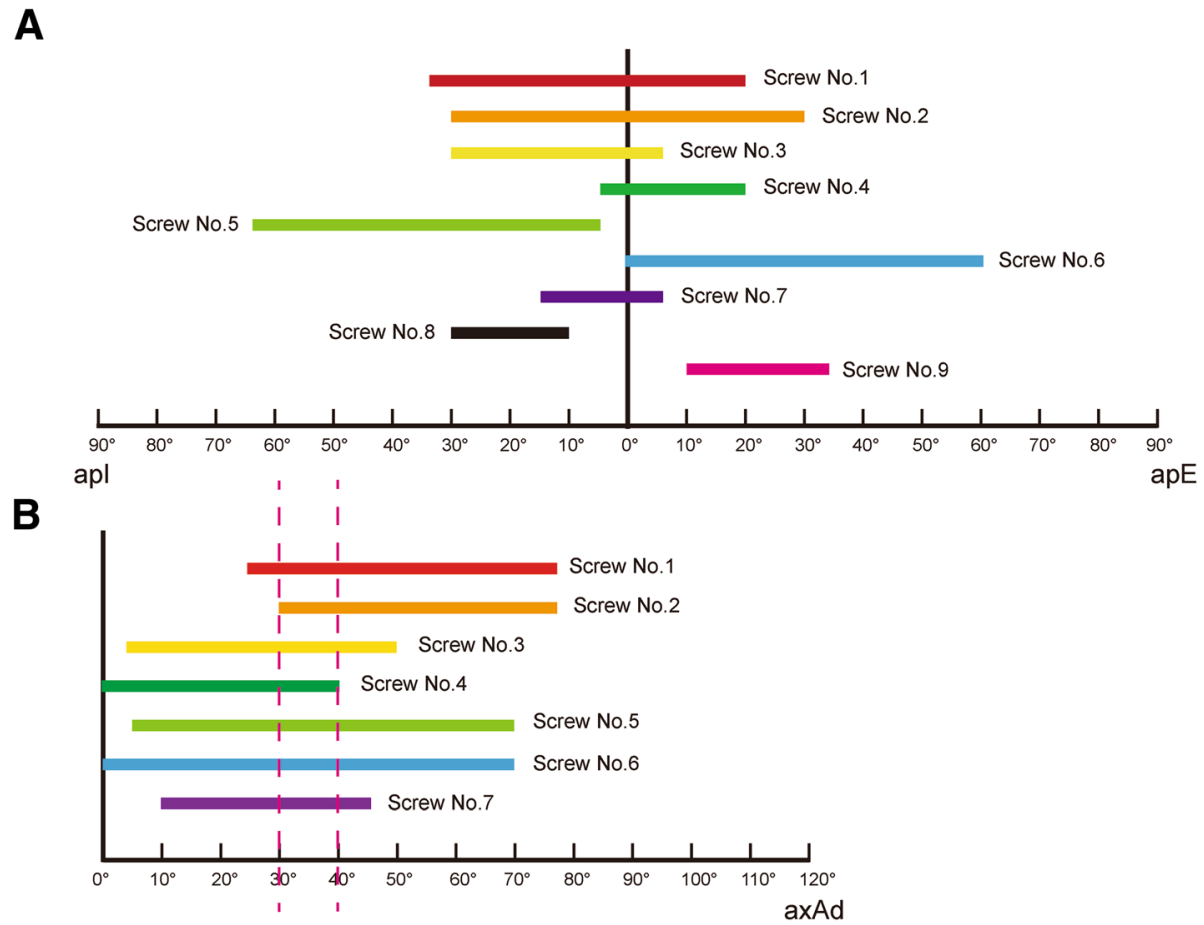

Fig. 8 The data in Fig. 7 can be converted into another type by swinging the arm rather than rotating the c-arm. apl: internal rotation of the arm in anteroposterior projections; apE: external rotation of the arm in anteroposterior projections; axAd: external abduction of the arm in axillary projections

abduction) presented the highest sensitivity in a single radiographic projection.

According to our data, the standard axillary view with the arm at $30^{\circ}$ abduction should be recommended, and the angles in the range between $0^{\circ}$ and $10^{\circ}$ (abduction 30 $40^{\circ}$ ) show the same high sensitivity. In the horizontal plane, at least two different projections should be used to detect screws No. 8 and 9, one in the range between $-30^{\circ}$ and $-10^{\circ}$, another between $10^{\circ}$ and $35^{\circ}$, which equate to internal rotation of the arm $10-30^{\circ}$ and external rotation of $10-35^{\circ}$. In addition, we found that the standard lateral view was not able to identify any screw penetration, which may be because $1 \mathrm{~mm}$ is too short to be detected. We recommend that our results should be used intraoperatively to reduce the rate of primary screw penetration rather than at follow-up. This is because, on the one hand, a large proportion of secondary screw penetrations are secondary to severe humeral head deformities, such as varus and necrosis, so that the optimal angles for these heads would be different from our data, while on the other hand, it may be impractical to perform fluoroscopy using such accurate angles at each follow-up.

In the process of carrying out this study, we chose to rotate the c-arm rather than rotate the arm (internal and external rotation), because it is easier and more precise to control the angle according to the angle indexes on the $\mathrm{c}-\mathrm{arm}$, and it is also more practical during surgery.
Based on our results, we can conclude that the sensitivity of every radiographic projection, for anteroposterior and outlet radiographs, means that penetration of three screws may be missed, while the result of a standard axillary view is similar to that found in the study by Spross et al., showing that it is sensitive to all screws but No. 8 and 9 . So we recommend $0^{\circ}-10^{\circ}$ axillary view with the arm at $30^{\circ}$ abduction combined with two horizontal angles in the range of $-30^{\circ}$ to $-10^{\circ}$ and $10^{\circ}$ to $35^{\circ}$ as a good combination; however, this is not the only one which can achieve $100 \%$ sensitivity, because the standard $0^{\circ}$ axillary view with the arm at $30^{\circ}$ abduction is used in many places and is easy to remember.

There are some limitations to this research. Firstly, the protocol was designed based on healthy shoulders with no history of bone diseases, so we simulated an anatomical reduction model. Although for some fractures it is difficult to obtain the absolute anatomical reduction [20], we believe a slight deformity can be acceptable under the angle ranges. Secondly, there are wide variations in the length of the screw tip clinically cut out of the head; we set all screws cut out of the head to $1 \mathrm{~mm}$, so shorter penetrations can still be missed under these views. Finally, we studied only one kind of plate. Although it is used commonly, the screws on this plate are divergently positioned in every section of the humeral head, so its unique design means that our data may be unsuitable for application to other implants. 


\section{Conclusion}

In conclusion, after studying the viewing angles of every proximal screw on PHILOS plate-fixed proximal humeral fractures, we obtained an optimal viewing angle range for every screw. Consequently, we recommend $0^{\circ}-10^{\circ}$ axillary view with the arm at $30^{\circ}$ abduction, while another two horizontal angles in the range of $-30^{\circ}$ to $-10^{\circ}$ and $10^{\circ}$ to $35^{\circ}$ should be included. Our results will be helpful for avoiding screw penetration during surgery.

\section{Abbreviation}

PHILOS: Proximal Humerus Internal Locking System

\section{Funding}

This study was supported by Three-year Project for Enhancing Clinical and Innovative Competence of Municipal Hospitals (16CR3042A).

\section{Availability of data and materials}

The datasets used and analysed during the current study are available from the corresponding author on reasonable request.

\section{Authors' contributions}

QW and $Y L$ designed and carried out the subject; $M Z$ and $Y Z$ wrote the article; LW and YC reviewed and edited the article. All authors read and approved the final manuscript.

\section{Ethics approval and consent to participate}

This study was approved by ethics of committee of Shanghai sixth people's hospital, the approval number is 2016-ky-005. The written consent was signed by patients before death at local red cross committee, and all these cadavers were obtained from the department of anatomy of Shanghai Jiao Tong University.

\section{Consent for publication}

Not applicable

\section{Competing interests}

The authors declare that they have no competing interests.

\section{Publisher's Note}

Springer Nature remains neutral with regard to jurisdictional claims in published maps and institutional affiliations.

Received: 21 January 2018 Accepted: 27 August 2018

Published online: 07 September 2018

\section{References}

1. Helwig P, Bahrs C, Epple B, Oehm J, Eingartner C, Weise K. Does fixed-angle plate osteosynthesis solve the problems of a fractured proximal humerus? Acta Orthop. 2009;80:92-6. https://doi.org/10.1080/17453670902807417.

2. Ricchetti ET, Warrender WJ, Abboud JA. Use of locking plates in the treatment of proximal humerus fractures. J Shoulder Elbow Surg. 2010;19: 66-75.

3. Yang $H, L i Z$, Zhou F, Wang D, Zhong B. A prospective clinical study of proximal humerus fractures treated with a locking proximal humerus plate. J Orthop Trauma. 2011;25(1):11-7. https://doi.org/10.1097/BOT. Ob013e3181d2d04c.

4. Clavert P, Adam P, Bevort A, Bonnomet F, Kempf JF. Pitfalls and complications with locking plate for proximal humerus fracture. J Shoulder Elb Surg. 2010;19(4):489-94. https://doi.org/10.1016/j.jse.2009.09.005.

5. Charalambous CP, Siddique I, Valluripalli $K$, Kovacevic M, Panose $P$, Srinivasan M, et al. Proximal humeral internal locking system (PHILOS) for the treatment of proximal humeral fractures. Arch Orthop Trauma Surg. 2007;127(3):205-10. https://doi.org/10.1007/s00402-006-0256-9.

6. Erasmo R, Guerra G, Guerra L. Fractures and fracture-dislocations of the proximal humerus: a retrospective analysis of 82 cases treated with the Philos((R)) locking plate. Injury. 2014:45(Suppl 6):S43-8. https://doi.org/10. 1016/j.injury.2014.10.022
7. Fazal MA, Haddad FS. Philos plate fixation for displaced proximal humeral fractures. J Orthop Surg. 2009;17(1):15-8. https://doi.org/10.1177/ 230949900901700104

8. Koukakis A, Apostolou CD, Taneja T, Korres DS, Amini A. Fixation of proximal humerus fractures using the PHILOS plate: early experience. Clin Orthop Relat Res. 2006:442:115-20.

9. Egol KA, Ong CC, Walsh M, Jazrawi LM, Tejwani NC, Zuckerman JD. Early complications in proximal humerus fractures (OTA types 11) treated with locked plates. J Orthop Trauma. 2008;22(3):159-64. https://doi.org/10.1097/ BOT.0b013e318169ef2a.

10. Gardner MJ, Weil Y, Barker JU, Kelly BT, Helfet DL, Lorich DG. The importance of medial support in locked plating of proximal humerus fractures. J Orthop Trauma. 2007;21(3):185-91. https://doi.org/10.1097/BOT. Ob013e3180333094.

11. Roderer G, Erhardt J, Kuster M, Vegt P, Bahrs C, Kinzl L, et al. Second generation locked plating of proximal humerus fractures--a prospective multicentre observational study. Int Orthop. 2011;35(3):425-32. https://doi. org/10.1007/s00264-010-1015-7.

12. Spross C, Jost B, Rahm S, Winklhofer S, Erhardt J, Benninger E. How many radiographs are needed to detect angular stable head screw cut outs of the proximal humerus - a cadaver study. Injury. 2014;45:1557-63. https://doi.org/ 10.1016/j.injury.2014.05.025.

13. Theopold J, Weihs K, Marquass B, Josten C, Hepp P. Detection of primary screw perforation in locking plate osteosynthesis of proximal humerus fracture by intra-operative 3D fluoroscopy. Arch Orthop Trauma Surg. 2017; 137:1491-8. https://doi.org/10.1007/s00402-017-2763-2.

14. Theopold J, Weihs K, Feja C, Marquass B, Josten C, Hepp P. Detection of articular perforations of the proximal humerus fracture using a mobile 3D image intensifier - a cadaver study. BMC Med Imaging. 2017;17:47. https:// doi.org/10.1186/s12880-017-0201-0.

15. Boesmueller S, Wech M, Gregori M, Domaszewski F, Bukaty A, Fialka C, et al. Risk factors for humeral head necrosis and non-union after plating in proximal humeral fractures. Injury. 2016;47(2):350-5. https://doi.org/10.1016/ j.injury.2015.10.001

16. Egol KA, Sugi MT, Ong CC, Montero N, Davidovitch R, Zuckerman JD. Fracture site augmentation with calcium phosphate cement reduces screw penetration after open reduction-internal fixation of proximal humeral fractures. J Shoulder Elb Surg. 2012;21(6):741-8. https://doi.org/10.1016/j.jse. 2011.09.017.

17. Fankhauser F, Boldin C, Schippinger G, Haunschmid C, Szyszkowitz R. A new locking plate for unstable fractures of the proximal humerus. Clin Orthop Relat Res. 2005:430:176-81.

18. Wang Q, Zhu Y, Liu Y, Wang L, Chen Y. Correlation between classification and secondary screw penetration in proximal humeral fractures. PLoS One. 2017;12(9):e0183164. https://doi.org/10.1371/journal.pone.0183164.

19. Thanasas C, Kontakis G, Angoules A, Limb D, Giannoudis P. Treatment of proximal humerus fractures with locking plates: a systematic review. J Shoulder Elb Surg. 2009:18(6):837-44. https://doi.org/10.1016/j.jse.2009.06.004.

20. Schnetzke M, Bockmeyer J, Porschke F, Studier-Fischer S, Grutzner PA, Guehring T. Quality of reduction influences outcome after locked-plate fixation of proximal humeral type-C fractures. J Bone Joint Surg Am. 2016; 98(21):1777-85. https://doi.org/10.2106/JBJS.16.00112.

Ready to submit your research? Choose BMC and benefit from:

- fast, convenient online submission

- thorough peer review by experienced researchers in your field

- rapid publication on acceptance

- support for research data, including large and complex data types

- gold Open Access which fosters wider collaboration and increased citations

- maximum visibility for your research: over $100 \mathrm{M}$ website views per year

At BMC, research is always in progress.

Learn more biomedcentral.com/submissions 